\title{
It's a funny old game
}

\author{
A diverse group of people with a range of skills is required to be successful in academia, just as it is in team sports, \\ argues Bruce C. Gibb.
}

\section{BREAKING NEWS: We've just learned that only a few short weeks before the} Covid-19-delayed Euro 2020 football tournament was due to start, the Scottish international team was embroiled in a massive internal dispute about final squad selection. The disruption broke out when unnamed higher-ups in the Scottish Football Association (SFA) pushed the idea to coach Steve Clark and his assistant John Carver that they ignore tradition and recent player form, but instead list a squad of twenty-six players composed entirely of strikers. The storm apparently arose after an SFA administrator read a controversial academic paper on artificial intelligence and its ability to select a winning football team. Evidently, one of the key measures of success was the so-called goal-index (g-index) and the researchers concluded from their findings that a squad composed entirely of strikers would score the most goals and, therefore, win Euro 2020.

Needless to say this idea did not sit well in the Scottish camp, with those in opposition to the idea pointing out that strikers usually do not make the best goalkeepers, defenders and midfielders, and that the team would let in more goals than they scored. As an anonymous source stated, "strikers only know how to stick the ball in the onion bag, they don't understand the complex process of getting the ball out of their own 18-yard box and down the field. Staunch defending, industry, power and creativity in midfield, the crossing ability of wingers, these are all foreign to strikers". Still, the controversial idea would not disappear, with the proponents pointing out that they - and science - know best, and it was time for the Scottish football team to get into the twenty-first century and fall behind the g-index. After all, history had shown that the Scottish team was not even capable of making the second round of a major tournament, never mind winning it. As one SFA insider who requested anonymity stated, "We've never been any good doing things the old way!"

As readers may be aware, this controversy was never made public until now, in large part because the opponents to it won the day; the SFA announced a squad of three goal keepers, ten defenders, seven midfielders, and only six strikers. The other reason why you might have missed

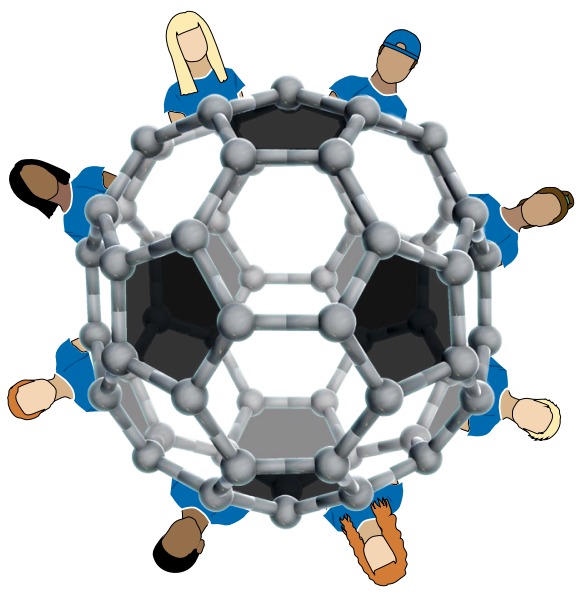

Credit: Science History Images / Alamy Stock Photo

this story is, of course, that it is pure fiction. What sort of coach would purposefully create a squad or team composed of only one kind of player? Netball, volleyball, baseball, basketball... name your favourite team sport. It takes much more than just one particular skillset to make up an effective team.

But isn't that what we do in academic STEM? Don't chemistry departments, to use a football metaphor, mostly target and hire strikers; preferably from Barcelona, Manchester City, Bayern Munich or Inter Milan? After all, the majority of chemistry departments have historically hired faculty - and continue to hire faculty - based on two narrow metrics: pedigree and productivity. An academic pedigree is, more often than not, key to make it through the first triage stage of the pool of (hundreds of) candidates. And once you're through, to make the next cut you'll likely need lots of publications in top-tier journals. Only then will the search committee read the letters of reference which, if well written, will contain a host of information about you the scientist; about you the person. Keep your fingers crossed and you'll have a Zoom interview, or better still, an actual campus visit where you'll meet potential colleagues.

The strangeness of university pecking order has been dissected time and time again - see, for example, Alexander Astin's perspective as it applies to undergraduate admissions $^{1}$ - so let's just assume your pedigree is second to none. To be in with a shot of a tenure-track academic position you also need to have scored goals, that is, to continue the analogy, published... as much as possible. And there is no denying that young pretender faculty have been playing this game and honing their striking skills with gusto; these days, many of the CVs of these young-guns are scarily impressive. Parenthetically, it takes a cool head to step back and appreciate the personal costs to the researcher; stretched so thin they risk snapping as they strive to fill the narrow metric of publications. And so, sticking with a footballing metaphor, the reality on the ground is that the current system is set-up to produce one kind of player: strikers.

Not surprisingly then, departments have an over-abundance of strikers; all convinced that their definition of 'smart' and 'success', and their modus operandi, is the only true way for advancing chemistry. These are Astin's 'maximizers', ${ }^{1,2}$, colleagues who prefer to demonstrate intellect rather than cultivate it, who like to demonstrate their 'smarts' by confidently trotting out endless data, facts and opinions, and who revel in being the arch critic who nixes any new idea that may arise in a committee meeting. Although criticism of ideas is essential, maximizers savour making criticism an end in itself, and their sheer number and methods mean that they wield undue influence on all aspects of the academy. It is, to put it mildly, a sad state-of-affairs. And pity the poor job candidate that a maximizer assesses is not up to par. Even thick skins have trouble withstanding crushing forces.

Now none of this is to say that strikers don't play a key role in academia. Published research and strong scholarship are essential to the job. And, let's admit it, fun. Everyone enjoys curling a 35-yarder into the top corner of the net; everyone enjoys knocking the ball out of the park and scoring a home run. But that, of course, is just one part of the game. Our problem as academicians is that metaphorically curling a 35-yarder into the top corner has become so important that it dominates our day-job almost completely. It's embedded in the culture - no, it is the culture - and it exists and thrives like any culture because it is self-fulfilling. We revel in the occasion when we strike gold, so being a 'heavy-hitter' is the administration's core metric of success. And, because this is 
how we're judged, we all go out of our way to be smart (publish) and successful (publish more). This is at the heart of the paradox that we are paid to educate, but educating is not how we earn.

How do we get out of this sticky situation? Not easily unfortunately. Any deviation from a prevailing culture - no matter how flawed that facet of a culture is - is viewed as uncivil at best and an anathema at worst. Dissidents, I would argue, have the hardest job.

The fundamental task for us academic chemists is to systematically put in place mechanisms that both force us to broaden our definition of 'smart' and remind us that 'success' comes in many guises. In the most general of terms, intelligence is the ability to perceive information, retain it, and then apply it forward and change our behaviour and/or environment. Our learn-and-churn (standardized) testing culture favours those who can quickly perceive information distilled onto paper in black and white, retain it for a specified time frame and then regurgitate it upon demand. By no coincidence whatsoever, it favours the strikers/maximizers. As individuals and academic units we need, therefore, to identify different kinds of people: the ruminators who absorb information slowly and evolve ideas on relatively long timescales, or those who can assess a multi-component, dynamic environment (such as a department) and assess its strengths and weaknesses.

To slip back to football again, a creative midfielder may not be a great goal scorer, but their ability to understand the flow of play at a particular moment, and understand how it is going to change with time, is key to them making intelligent passes' and dictating the game. Similarly, as academics we need to be able to identify stout defenders who know where to position themselves in order to protect the team from distractions that are not core to the job. And just to pick one more example, as individuals and academic units we need to identify the creatives; those who can link disparate nuggets of knowledge, synthesize new ideas and change their environment in a completely unexpected way. If we can identify these people, hire them and nurture them; if we can carve within our departments facets of leadership, creativity, critical thinking, citizenship and empathy, we can succeed.

There's no shortcut here, no secret sauce recipe. We need hard work, patience, diligence and diversity in all its forms... over multiple generations of chemists. But if we all do our bit, chemistry departments can evolve. After all, if football can understand the strength in diversity, surely academia can too.

\section{Bruce C. Gibb}

Department of Chemistry, Tulane University, New Orleans, LA, USA.

Twitter: @brucecgibb

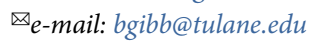

Published online: 30 July 2021

https://doi.org/10.1038/s41557-021-00768-1

References

1. Astin, A. W. Are You Smart Enough? (Stylus Publishing LLC, 2016).

2. Astin, A. W. Our obsession with being 'smart' is distorting intellectual life. The Chronicle of Higher Education https:// www.chronicle.com/article/our-obsession-with-being-smartis-distorting-intellectual-life/ (1997).

Competing interests

The author declares no competing interests. 